\title{
Avaliação dos efeitos da fibra de coco e da microcelulose cristalina nas propriedades de argamassas cimentícias
}

\section{Evaluation of the effects of coconut fiber and microcellulose crystalline on the properties of cementitious mortars}

Luana Jéssica Capelin ${ }^{1}$, Katherine Kaneda Moraes ${ }^{1}$, João Paulo Zampieri ${ }^{1}$, Romel Dias Vanderlei ${ }^{1}$

\footnotetext{
${ }^{1}$ Departamento de Engenharia Civil, Universidade Estadual de Maringá, Maringá, PR, Brasil. e-mail: luanacapelinengcivil@gmail.com, katherinekaneda@hotmail.com, joaopaulozamp2940@gmail.com, rdvanderlei@uem.br.
}

\section{RESUMO}

Os materiais cimentícios são os mais utilizados mundialmente, na construção civil. Frente a isso, pesquisas são necessárias para melhorar tanto seu desempenho mecânico quanto seu desenvolvimento sustentável. Uma alternativa que busca essas melhorias é a adição de materiais de origem vegetal, como por exemplo, a fibra de coco e a microcelulose cristalina. Sendo assim, o objetivo do presente trabalho foi avaliar a influência das adições de fibra de coco (FC) e microcelulose cristalina (MCC) nas propriedades físicas e mecânicas de argamassas cimentícias. Para um melhor delineamento da pesquisa, esta foi dividida em três fases: caracterização dos materiais; análise de argamassas com adições de FC e argamassas com adições de MCC; análise de argamassas com adições de FC e MCC simultaneamente. Foram realizados os seguintes ensaios: índice de consistência, resistência à compressão, resistência à tração na flexão, módulo de elasticidade, absorção de água, índice de vazios, massa específica, Microscopia Eletrônica de Varredura (MEV) e Espectrografia por Dispersão de Energia (EDS). Os resultados encontrados demonstram que as incorporações de FC e MCC em teores acima de $0,2 \mathrm{FC}$ e $0,3 \mathrm{MCC}$ melhoram de forma significativa o desempenho das argamassas quanto a resistência à tração na flexão, porém não contribuem de forma positiva nas outras propriedades mecânicas das argamassas, mas sem prejuízos significativos para sua utilização. É recomendável estudos de argamassas com FC e MCC a longo prazo para verificar se as propriedades mecânicas sofrem influências significativas com a idade.

Palavras-chave: Compósitos cimentícios. Fibra de coco. Microcelulose cristalina. Materiais de construção alternativos.

\section{ABSTRACT}

The cementitious materials are the most used worldwide, in civil construction. Faced with this, research is needed to improve both its mechanical performance and its sustainable development. An alternative that seeks these improvements is the addition of materials of vegetable origin, such as coconut fiber and microcellulose crystalline. Therefore, the objective of the present work was to evaluate the influence of additions of coconut fiber (CF) and microcellulose crystalline (MCC) on the physical and mechanical properties of cementitious mortars. For a better delineation of the research, it was divided into three phases: characterization of the materials; analysis of mortars with additions of CF and mortars with MCC additions; analysis of mortars with additions of CF and MCC simultaneously. The following tests were performed: consistency index, compressive strength, flexural tensile strength, modulus of elasticity, water absorption, void index, specific mass, Scanning Electron Microscopy (SEM) and Energy Dispersive Spectroscopy (EDS). The results show that the incorporations of $\mathrm{CF}$ and $\mathrm{MCC}$ in contents above $0.2 \mathrm{CF}$ and $0.3 \mathrm{MCC}$ significantly improve the performance of mortars in terms of tensile strength in flexion, however do not contribute positively to the other mechanical properties of mortars, but without significant damage to its use. Studies of mortars with long- 
term $\mathrm{CF}$ and $\mathrm{MCC}$ are recommended to verify if mechanical properties undergo significant influences with age.

Keywords: Cementitious composites. Coconut fiber. Microcellulose crystalline. Alternative building materials.

\section{INTRODUÇÃO}

No Brasil e no mundo, os materiais de construção mais utilizados são aqueles provenientes do cimento Portland, como os concretos e as argamassas. A sua ampla utilização está ligada ao fato de que estes materiais possuem diversas vantagens como, fácil moldabilidade, boa resistência mecânica, durabilidade, boa resistência à água, custo menor quando comparado a outros materiais construtivos e dentre outras qualidades. Apesar destas vantagens, esses materiais também apresentam algumas desvantagens, como por exemplo: tem um peso elevado, comportamento frágil, sua microestrutura é heterogênea e complexa, há dificuldade em prever com precisão o comportamento do material, ou seja, apenas depois de 28 dias é possível verificar se atendeu os requisitos de desempenho estrutural projetado. Além dessas desvantagens, existe também a preocupação em relação à ampla utilização de recursos naturais e os altos índices de emissões de gases poluentes que ocorrem na produção do cimento. Diante do exposto, pesquisas são necessárias para se melhorar tanto as características de desempenho mecânico, quanto um melhor desenvolvimento sustentável dos materiais cimentícios.

Para melhorar o desempenho dos materiais cimentícios, diminuir o impacto ambiental e ter um menor custo, pode-se fazer a adição de materiais de origem vegetal, que tem como objetivo então, atuar como material de reforço em compósitos cimentícios. As vantagens em se fazer a adição de materiais vegetais, é que eles são caracterizados como um recurso renovável, pois sua extração é proveniente de várias fontes vegetais como bambu, diversos tipos de madeira, sisal, coco, bagaço da cana-de-açúcar, etc. Têm baixo custo, ampla disponibilidade, melhora o desempenho dos materiais cimentícios no que diz respeito ao comportamento pósfissuração, tornando o material mais dúctil, as fibras se distribuem de forma aleatória no material, o que faz com que o reforço aconteça em toda a peça e não em uma só localidade, como ocorre com as armaduras convencionais. E as desvantagens é que sua durabilidade ainda é questionável no meio altamente alcalino dos materiais cimentícios, ou seja, por se tratar de um material orgânico, pode vir a sofrer degradação ao longo do tempo, têm também alta capacidade de absorver água, o que faz com que diminua a trabalhabilidade dos compósitos cimentícios no estado fresco [1,2].

Uma fibra natural que tem sido estudada como adição em material cimentício é a fibra de coco (FC), a qual é extraída da casca do coco. Segundo o Instituto Brasileiro de Geografia e Estatística (IBGE), pelo Levantamento Sistemático da Produção Agrícola (LSPA), a produção de coco no Brasil no ano de 2017, foi de 20.958.641 frutos. A casca do coco que tem em média $900 \mathrm{~g}$ de massa e rende aproximadamente $30 \%$ de fibra [3]. Desta forma, se todas as cascas dos cocos forem aproveitadas, poderiam ser gerados então, em torno de 5660 toneladas de fibras.

As fibras de coco $(\mathrm{FC})$ possuem uma elevada resistência à tração, conforme aponta na literatura, em que mostram valores de $105,97 \mathrm{MPa}$ até $286,00 \mathrm{MPa}$ [4,5,6,7]. As propriedades da FC são variáveis e isto pode ser atribuído as diferentes condições edafoclimáticas (condições do solo e clima) da região em que é cultivado, a adubação, como é realizado e mantido o plantio e a variedade de espécie cultivada [3].

No trabalho de SILVA et al. [8] foram produzidas argamassas cimentícias com adições de FC in natu$r a$ com diferentes comprimentos $(12,5 ; 25,0 ; 37,5 ; 50,0 ; 62,5$ e 75,0 mm) e com um teor de adição de $0,3 \%$ em relação ao volume do compósito. $\mathrm{O}$ traço utilizado foi o 1:2,3:0,55 (cimento:agregado miúdo: relação água/cimento). Foram realizados os ensaios de índice de consistência e de resistência à compressão aos 7, 28 e 56 dias. Em relação ao índice de consistência, as argamassas com as fibras maiores $(50,0 ; 62,5$ e 75,0 mm) tiveram uma redução significativa na consistência. Já para os outros comprimentos, não houve mudanças significativas nesta propriedade. E em relação à resistência à compressão, todas as argamassas com adições, tiveram valores menores quando comparados ao de referência. A argamassa que teve o melhor desempenho foi a com FC de 25,0 mm. Mesmo tendo valores menores de resistência à compressão, os autores demonstraram que as fibras com $25,0 \mathrm{~mm}$ promoveram a ligação entre as partes fissuradas, de modo que se evitou a ruptura brusca da peça ensaiada. E também os valores de resistência à compressão de todas as argamassas com adições, ficaram superiores ao valor mínimo exigido pela ABNT NBR 6118 [9].

Um outro material vegetal investigado recentemente, como adição em matrizes cimentícias, é a microcelulose cristalina (MCC). Este produto é utilizado em diversos seguimentos industriais, como a farmacêutica, alimentícia e de cosméticos. Tem ótimo módulo de elasticidade, cerca de $150 \mathrm{GPa}$, que é superior a fibras de vidro que tem $85 \mathrm{GPa}$ e fibras de aramida que tem $65 \mathrm{GPa}$ [10]. 
No trabalho de HOYOS et al. [10], foram produzidas pastas e argamassas cimentícias com adição de $3 \%$ de MCC em relação a massa de cimento. O traço utilizado para as pastas foi 1:0,45 (cimento:água) e para as argamassas 1:2,7:0,45 (cimento:agregado miúdo:água). A MCC foi saturada em água durante 2 dias. Foram realizados dois processos de cura, o acelerado e o regular, e diversos ensaios. Com base nos resultados, os autores concluíram que a MCC diminui a trabalhabilidade das argamassas, na cura acelerada as argamassas tiveram desempenho superior e que os compósitos com adição de MCC tem potencial de uso em elementos pré-moldados e em estruturas maciças para reduzir a fissuração causada pela retração.

Neste contexto, com o intuito de contribuir para a melhoria da qualidade de materiais cimentícios, seu desenvolvimento sustentável e em avanços em pesquisas com esses materiais alternativos, o presente trabalho teve por objetivo analisar a influência da adição de FC e MCC nas propriedades físicas e mecânicas de argamassas cimentícias.

\section{MATERIAIS E MÉTODOS}

A pesquisa foi dividida em três fases, sendo elas:

Fase 1 - Preparo e caracterização dos materiais;

Fase 2 - Avaliação de argamassas com FC e argamassas com MCC, a fim de determinar teores ótimos de FC e MCC;

Fase 3 - Avaliação de argamassas com adições de FC e MCC simultaneamente.

Cada fase será descrita nos itens apresentados a seguir.

\subsection{Materiais}

Os materiais utilizados para a produção das argamassas foram:

- Cimento Portland de Alta Resistência Inicial - CP V ARI: a escolha por este cimento se deu pelo fato de ter uma composição mais pura (sem quantidade significativa de adições), objetivando diminuir o número de variáveis no compósito, de maneira que as adições contidas nos cimentos compostos não interfiram na análise dos resultados, possibilitando uma análise mais precisa dos efeitos da FC e MCC em compósitos com pouca adições minerais.

- Agregado miúdo: areia natural fluvial, massa específica de 2,65 g/ $\mathrm{cm}^{3}$, massa unitária de 1,49 g/cm³, módulo de finura 1,97, diâmetro máximo característico \#1,2 mm.

- Água de amassamento: água proveniente da rede de abastecimento local.

- FC: obtida no comércio local em sacos de 200 g em seu estado natural (sem nenhum tipo de adição química ou beneficiamento). A fibra utilizada pode ser considerada como um resíduo, pois é proveniente de diversas cascas de coco, de frutos verdes e maduros e de variadas espécies. Desta forma, é um material que possui heterogeneidade em suas propriedades. Apesar deste fator, optou-se por utilizar esta fibra devido ao fato de ter um baixo custo e sua fácil disponibilidade no mercado local, o que então torna-se mais vantajoso do ponto de vista sustentável. A Figura 1 mostra a FC in natura.

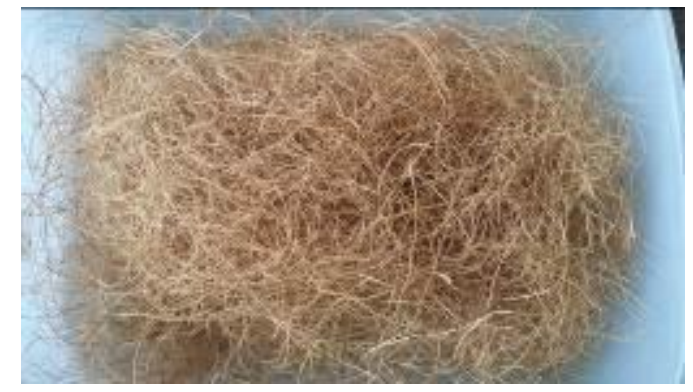

Figura 1: Fibra de Coco (FC) in natura.

- MCC: A MCC utilizada foi em pó e produzida a partir do algodão. As características da MCC, conforme dados do fabricante, são descritas na Tabela 1 e a MCC é mostrada na Figura 2. 


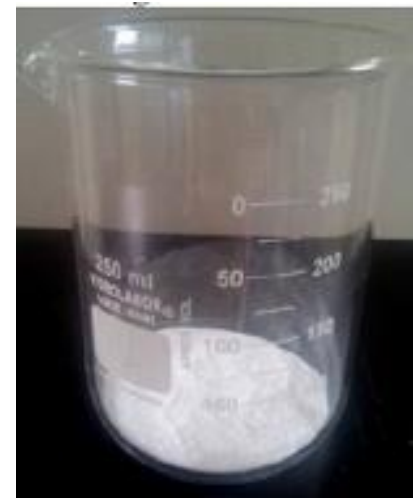

Figura 2: Microcelulose cristalina - MCC.

Tabela 1: Especificações da MCC.

\begin{tabular}{c|c}
\hline \multicolumn{2}{c}{ MICROCELULOSE CRISTALINA - MCC } \\
LABORATÓRIO: SIGMA ALDRICH CORPORATION \\
\hline ANÁLISE & ESPECIFICAÇÃo \\
\hline Aparência (cor) & Branca ou praticamente branca \\
\hline Aparência (forma) & Pó \\
\hline Resíduo na ignição & $\leq 0,1 \%$ \\
\hline Metais pesados & $\leq 0,001 \%$ \\
\hline Ph & $4,5-7,5$ \\
\hline Densidade (g/ml) & 0,6 \\
\hline Tamanho da partícula (+60 mesh) & $\leq 10 \%$ \\
\hline Tamanho da partícula (+200 mesh) & $\geq 40 \%$ \\
\hline Perda na secagem & $\leq 7 \%$ \\
\hline Tamanho da partícula & $51 \mu \mathrm{m}$ \\
\hline Cheiro & Inodora \\
\hline
\end{tabular}

\subsection{Fase 1 - Preparo e caracterização dos materiais}

Nesta fase foram realizados os seguintes procedimentos:

- Em relação a FC: corte, tratamento, cálculo do fator de forma da FC tratada, massa específica da FC tratada e Microscopia Eletrônica de Varredura (MEV) nas FC in natura e tratada; Willey.

Para diminuir o comprimento da FC in natura, foi realizado seu corte em um moinho de facas tipo

O tratamento realizado foi escolhido com base nos trabalhos de ALI et al. [11] e ASASUTJARIT et al. [12] e se deu da seguinte forma: as fibras foram colocadas em água fervente durante duas horas. Após, foram lavadas com água corrente a temperatura ambiente até que a cor da água ficasse clara. Em seguida, foram colocadas para secar ao sol durante dois dias. O processo de fervura elimina sujeiras impregnadas, reduz algumas substâncias orgânicas, como os açúcares, amido, gordura, taninos, resinas, quininos e fenóis, por isso a água fica com coloração marrom escura após o processo de fervura [12].

Para o cálculo do fator de forma (relação entre comprimento/diâmetro), foi coletada aleatoriamente uma amostra com 50 fibras cortadas e tratadas. Os comprimentos foram medidos com um paquímetro digital e os diâmetros com um microscópio óptico. A medida do diâmetro foi realizada aproximadamente no ponto médio da fibra.

Para o cálculo da massa específica, foi realizado o mesmo procedimento descrito na ABNT NBR NM 52 [13], que diz respeito ao cálculo da massa específica do agregado miúdo.

E o MEV foi realizado com o objetivo de verificar a modificação ocorrida na superfície da fibra com o tratamento realizado.

- Em relação ao agregado miúdo: foram determinados a massa específica, massa unitária e composição gra- 
nulométrica, seguindo os procedimentos descritos nas ABNT NBR NM 52 [13], ABNT NBR NM 45 [14] e ABNT NBR NM 248 [15], respectivamente.

\subsection{Fase 2 - Avaliação de argamassas com FC e argamassas com MCC}

Nesta fase foram produzidas argamassas com os seguintes teores de adição de FC: 0,0 (referência), 0,1\%, $0,2 \%, 0,3 \%, 0,4 \%$ e $0,5 \%$ em relação ao volume do compósito. Estes valores de adição foram escolhidos baseados no trabalho de TOLEDO FILHO [16] em que mostrou que o melhor teor de adição de FC está entre $0,1 \%$ e $0,5 \%$. E também argamassas com os seguintes teores de MCC: 0,0 (referência), $0,1 \%, 0,2 \%, 0,3 \%$, $0,4 \%$ e $0,5 \%$ em relação à massa do cimento. Estes teores foram escolhidos baseado nos trabalhos de CAO et al. [17] e SILVA [18] que obtiveram os melhores resultados com porcentagens de adição em torno de $0,2 \%$.

As argamassas foram produzidas em ambiente com controle de temperatura que ficava em torno de 25 ${ }^{\circ} \mathrm{C}$. O traço utilizado para produção de todas as argamassas foi o 1:3:0,52 (cimento: agregado miúdo: relação água/cimento) em massa. A escolha deste traço (1:3) se deu com base na ABNT NBR 7215 [19], que especifica o ensaio de determinação da resistência à compressão do Cimento Portland. E a relação água/cimento foi definida por meio de análises preliminares em que se buscou um índice de consistência de $230 \mathrm{~mm} \pm 10 \mathrm{~mm}$ para argamassa sem adição. Com as adições era esperada a diminuição da trabalhabilidade, pois a FC e a MCC são materiais orgânicos e de caráter hidrofílico, ou seja, tem grande capacidade de absorver água, o que diminui então a consistência da argamassa [10].

O consumo de materiais em quilos para produzir um metro cúbico $\left(\mathrm{kg} / \mathrm{m}^{3}\right)$ de argamassa, é apresentado na Tabela 2.

Tabela 2: Consumo de materiais $\left(\mathrm{kg} / \mathrm{m}^{3}\right)$.

\begin{tabular}{c|c|c|c|c|c}
\hline \multirow{2}{*}{ ARGAMASSAS } & \multicolumn{5}{|c}{ CONSUMO DE MATERIAIS $\left(\mathbf{k g} / \mathbf{m}^{3}\right)$} \\
\cline { 2 - 6 } & Cimento & Agregado miúdo & Água & MCC & FC \\
\hline REF & 508,09 & 1524,27 & 264,20 & - & - \\
\hline $0,1 \mathrm{MCC}$ & 508,09 & 1524,27 & 264,20 & 0,50 & - \\
\hline $0,2 \mathrm{MCC}$ & 508,09 & 1524,27 & 264,20 & 1,01 & - \\
\hline $0,3 \mathrm{MCC}$ & 508,09 & 1524,27 & 264,20 & 1,52 & - \\
\hline $0,4 \mathrm{MCC}$ & 508,09 & 1524,27 & 264,20 & 2,03 & - \\
\hline $0,5 \mathrm{MCC}$ & 508,09 & 1524,27 & 264,20 & 2,54 & - \\
\hline $0,1 \mathrm{FC}$ & 508,09 & 1524,27 & 264,20 & - & 1,20 \\
\hline $0,2 \mathrm{FC}$ & 508,09 & 1524,27 & 264,20 & - & 2,41 \\
\hline $0,3 \mathrm{FC}$ & 508,09 & 1524,27 & 264,20 & - & 3,61 \\
\hline $0,4 \mathrm{FC}$ & 508,09 & 1524,27 & 264,20 & - & 4,82 \\
\hline $0,5 \mathrm{FC}$ & 508,09 & 1524,27 & 264,20 & - & 6,03 \\
\hline
\end{tabular}

As argamassas foram produzidas em argamassadeira automática, a qual está programada com os tempos e velocidades determinadas pela ABNT NBR 7215 [19].

Os procedimentos de produção das argamassas se deram da seguinte forma:

- Argamassa de referência: primeiro foi adicionada a água, em seguida o cimento com o agregado miúdo (os quais foram previamente misturados) e então se iniciou o processo de mistura.

- Argamassa com MCC: O procedimento foi adaptado do trabalho de SILVA [18]. A MCC foi colocada em parte da água de amassamento $(225 \mathrm{ml})$ para sua total saturação, onde permaneceu durante 48 horas. Antes de iniciar a produção da argamassa, a MCC foi agitada durante 45 minutos em agitador magnético para promover sua dispersão. Na cuba da argamassadeira, foi adicionado o restante da água de amassamento, o cimento e o agregado miúdo misturados previamente, a argamassadeira foi ligada e a MCC agitada foi adicionada.

- Argamassa com FC: foram produzidas de forma análoga ao de referência. As fibras foram adicionadas lentamente e espalhadas por toda a mistura assim que ligada a argamassadeira. Desta forma, evitou-se o agrupamento das fibras.

Nesta fase foram realizados os seguintes ensaios: índice de consistência no estado fresco [19], resistência à compressão aos 28 dias [19] e resistência à tração na flexão aos 28 dias [20]. 


\subsection{Fase 3 - Avaliação de argamassas com adições de FC e MCC simultaneamente}

Nesta fase foram produzidas argamassas de referência, com o teor ótimo de MCC, teor ótimo de FC e mais cinco diferentes argamassas com FC+MCC. Com o objetivo de conferir maior confiabilidade aos resultados, a seguinte metodologia foi proposta: uma argamassa com adição do teor ótimo de FC mais o teor ótimo de MCC; outras duas argamassas com o teor ótimo de MCC fixo e fez-se a variação de FC de 0,1 para mais e 0,1 para menos; e outras duas argamassas de forma inversa, com o teor ótimo da FC fixo e a variação do teor ótimo de $\mathrm{MCC}$ em 0,1 a mais e 0,1 a menos.

Foram produzidas as seguintes argamassas, com base nos teores ótimos escolhidos: REF (sem adições); $0,2 \mathrm{FC} ; \quad 0,3 \mathrm{MCC} ; \quad 0,2 \mathrm{FC}+0,3 \mathrm{MCC} ; \quad 0,1 \mathrm{FC}+0,3 \mathrm{MCC} ; \quad 0,3 \mathrm{FC}+0,3 \mathrm{MCC} ; \quad 0,2 \mathrm{FC}+0,2 \mathrm{MCC}$; $0,2 \mathrm{FC}+0,4 \mathrm{MCC}$. O consumo de materiais em quilos para produzir um metro cúbico $\left(\mathrm{kg} / \mathrm{m}^{3}\right)$ de argamassa, é apresentado na Tabela 3.

Tabela 3: Consumo de materiais $\left(\mathrm{kg} / \mathrm{m}^{3}\right)$.

\begin{tabular}{c|c|c|c|c|c}
\hline \multirow{2}{*}{ ARGAMASSAS } & \multicolumn{5}{|c}{ CONSUMO DE MATERIAIS $\left(\mathbf{k g} / \mathbf{m}^{3}\right)$} \\
\cline { 2 - 6 } & Cimento & Agregado miúdo & Água & MCC & FC \\
\hline REF & 508,09 & 1524,27 & 264,20 & - & - \\
\hline $0,2 \mathrm{FC}$ & 508,09 & 1524,27 & 264,20 & - & 2,41 \\
\hline $0,3 \mathrm{MCC}$ & 508,09 & 1524,27 & 264,20 & 1,52 & - \\
\hline $0,2 \mathrm{FC}+0,3 \mathrm{MCC}$ & 508,09 & 1524,27 & 264,20 & 1,52 & 2,41 \\
\hline $0,1 \mathrm{FC}+0,3 \mathrm{MCC}$ & 508,09 & 1524,27 & 264,20 & 1,52 & 1,20 \\
\hline $0,3 \mathrm{FC}+0,3 \mathrm{MCC}$ & 508,09 & 1524,27 & 264,20 & 1,52 & 3,61 \\
\hline $0,2 \mathrm{FC}+0,2 \mathrm{MCC}$ & 508,09 & 1524,27 & 264,20 & 1,01 & 2,41 \\
\hline $0,2 \mathrm{FC}+0,4 \mathrm{MCC}$ & 508,09 & 1524,27 & 264,20 & 2,03 & 2,41 \\
\hline
\end{tabular}

O traço e o procedimento de produção foi o mesmo da Fase 2. As argamassas com a dupla adição foi realizada da seguinte forma: na cuba da argamassadeira foi adicionado o restante da água de amassamento, o cimento e o agregado miúdo previamente misturados, a argamassadeira foi ligada e então foi adicionada a MCC agitada e a FC da mesma forma descrita na Fase 2.

Nesta fase foram realizados os seguintes ensaios: índice de consistência [19], resistência à compressão aos 3, 7, 28 e 56 dias [19], resistência à tração na flexão aos 28 dias [20], módulo de elasticidade aos 28 dias [21], absorção, índice de vazios e massa específica [22], e Microscopia Eletrônica de Varredura (MEV) e Espectroscopia de energia dispersiva (EDS) das argamassas aos 56 dias.

As análises com o MEV e o EDS foram feitas na face da FC e na interface da FC com a matriz cimentícia. A MCC não foi localizada nas amostras. Estas análises teve por objetivo averiguar a ligação da fibramatriz e também por meio do EDS obter a quantidade em porcentagem dos compostos químicos: $\mathrm{Si}, \mathrm{Ca}, \mathrm{Al}$ e Fe (silício, cálcio, alumínio e ferro). Com estes valores foram realizadas as correlações para verificar a fase da amostra. As relações utilizadas foram retiradas do trabalho de TAYLOR e NEWBURY [23] e são mostradas na Tabela 4.

Tabela 4: Relações das fases sólidas.

\begin{tabular}{c|c|c|c}
\hline Si/Ca & $(\mathbf{A l + F e}) / \mathbf{C a}$ & FASES & DEFINIÇÃO \\
\hline$\geq 0,4$ & $<0,2$ & C-S-H & $\begin{array}{c}\text { Silicato de cálcio hidratado: é a fase mais importante para as propriedades } \\
\text { das argamassas }\end{array}$ \\
\hline$<0,1$ & $<0,1$ & $\mathrm{CH}$ & Hidróxido de cálcio: apresenta baixa resistência química a soluções alcalinas \\
\hline$<0,5$ & $\geq 0,2$ & Etringita & Baixa resistência a sulfatos \\
\hline
\end{tabular}




\section{RESULTADOS E DISCUSSÕES}

\subsection{Fase 1 - Preparo e caracterização dos materiais}

Para avaliar o fator de forma da FC, foi produzido um gráfico de frequência em que se utilizaram cinco faixas de valores de fator de forma: 0 a 50, 50 a 100, 100 a 150, 150 a 200 e 200 a 250. Este método foi utilizado devido a amostra analisada apresentar heterogeneidade. No trabalho de BASTOS [24], a faixa típica de fator de forma para fibras com comprimentos entre 0,64 e 7,6 cm, como é o caso da fibra utilizada neste estudo, é em torno de 30 a 150. A Figura 3 mostra o resultado desta análise.

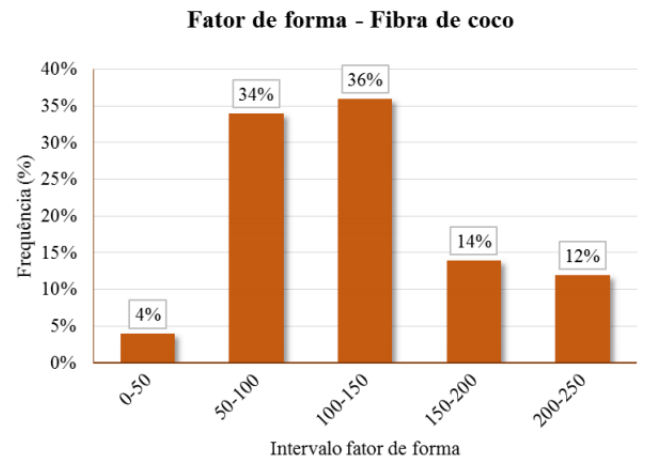

Figura 3: Fator de forma da FC.

Conforme mostra a Figura 3, a maior parte da amostra analisada (70\%) ficou na faixa de 50 a 150, que é então a faixa recomendada por BASTOS [24].

$O$ resultado encontrado para a massa específica da FC tratada foi de $1,206 \mathrm{~g} / \mathrm{cm}^{3}$.

E em relação ao MEV, a Figura 4 mostra a FC in natura e a tratada.

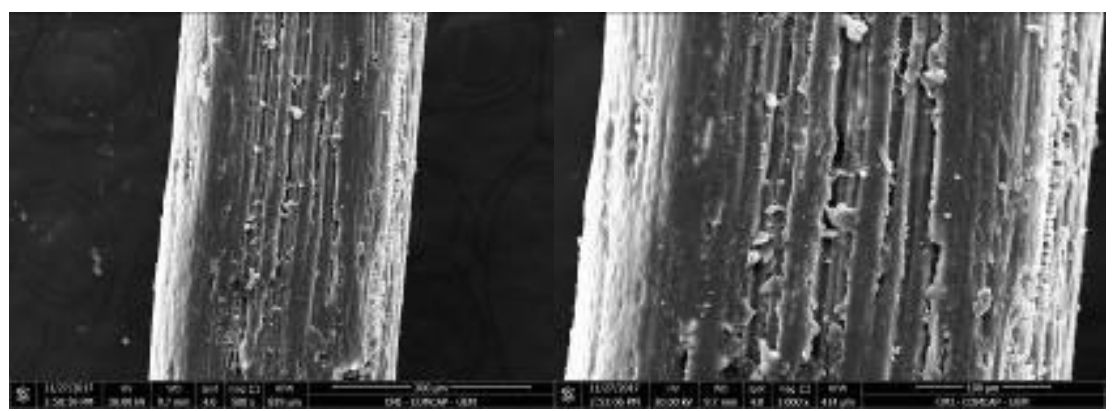

(a)

(b)

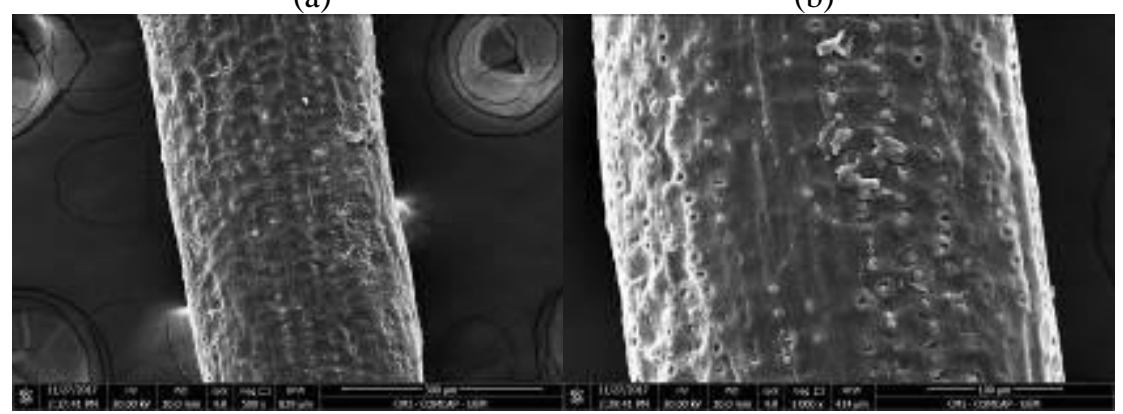

(c)

(d)

Figura 4: (a) FC in natura com magnificação de 500x (b) FC in natura com magnificação de 1000x (c) FC tratada com magnificação de 500x (d) FC tratada com magnificação de 1000x.

Conforme mostra a Figura 4, é possível observar uma considerável modificação na superfície da fibra. Esta modificação pode ser atribuída ao fato de que o processo de fervura extrai algumas substâncias orgânicas das fibras tornando sua superfície mais compacta e aparentemente enrijecida, corroborando com as conclusões de ASASUTJARIT [12]. 
Percebe-se nessa análise que o tratamento das fibras altera suas características superficiais, podendo produzir alterações significativas em suas propriedades mecânicas e de durabilidade no meio cimentício. No entanto, este estudo não teve por objetivo estudar o tratamento das FC e suas conseqüências, o que será abordado em outros trabalhos. Neste trabalho, buscou-se fixar o tratamento das FC para todas as argamassas, para que essa variável não interferisse de forma significativa na análise dos resultados.

\subsection{Fase 2 - Avaliação de argamassas com FC e argamassas com MCC}

Para a avaliação do índice de consistência, neste estudo foi considerado o valor mínimo de espalhamento de $180 \pm 10 \mathrm{~mm}$, como o menor para a manutenção das condições de boa trabalhabilidade do compósito. Sendo assim, o índice de consistência de todas as argamassas produzidas determinaram argamassas com boa trabalhabilidade. Com as maiores adições o índice de consistência foi: $184 \mathrm{~mm}$ para a argamassa com 0,5FC e 196 mm para a argamassa com 0,5MCC. Desta forma, não foi necessário utilizar aditivos superplastificantes.

Os resultados dos ensaios de resistência à compressão e à tração na flexão aos 28 dias, conforme trabalho de CAPELIN [25], determinaram como teores ótimos de adição os valores de $0,2 \%$ de FC e $0,3 \%$ de MCC. O teor de 0,2\% de FC teve um valor de resistência à compressão 2,14\% maior que a argamassa de referência (sem adição). A partir da adição de $0,3 \%$ de FC a resistência à compressão começou a diminuir, mas ainda assim os valores ficaram próximos ao de referência. E em relação à resistência à tração na flexão, todas as argamassas com FC tiveram desempenho superior à argamassa de referência. A argamassa com 0,2\% de FC teve um valor de resistência à tração na flexão de 59,59\% maior que a argamassa de referência.

A argamassa com $0,3 \%$ de MCC teve um valor de resistência à compressão de 4,24\% maior quando comparado à argamassa de referência. Em relação à resistência à tração na flexão, teve um aumento de $29,83 \%$ quando comparado à argamassa de referência. Com a adição de 0,5\% de MCC, as resistências começaram a diminuir.

Outro fator que foi levado em consideração para a determinação dos teores ótimos, foi o índice de consistência. Optou-se por menores adições, que também tiveram desempenho satisfatório, para que as argamassas tivessem uma boa trabalhabilidade e não precisassem utilizar aditivo superplastificante.

\subsection{Fase 3 - Avaliação de argamassas com adições de FC e MCC simultaneamente}

Nesta fase, para a avaliação do índice de consistência, também foi utilizado o valor de espalhamento de $180 \pm 10 \mathrm{~mm}$, como o mínimo para a manutenção das condições de boa trabalhabilidade do compósito. Sendo assim, todas as argamassas apresentaram uma faixa boa de trabalhabilidade, conforme mostra a Figura 5. A que teve o menor valor foi a argamassa $0.2 \mathrm{FC}+0,4 \mathrm{MCC}$, com um valor de $190 \mathrm{~mm}$.

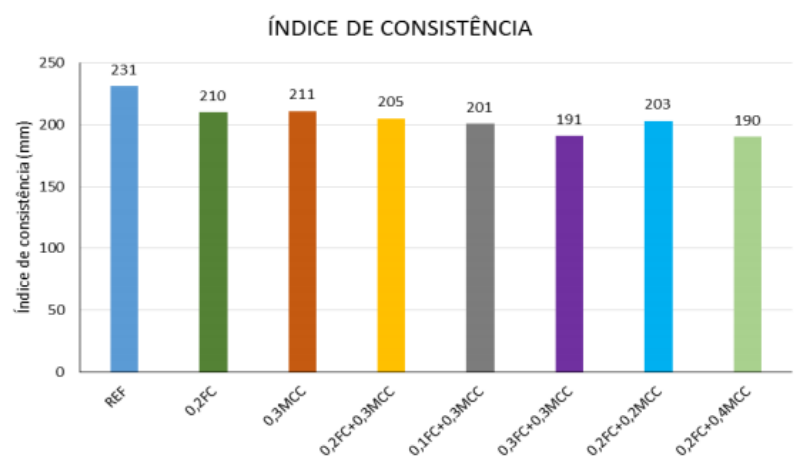

Figura 5: Índice de consistência das argamassas

Para os resultados do índice de consistência foi realizada uma análise estatística de regressão múltipla. Com esta análise foi possível obter uma equação (Equação 1), para encontrar o valor aproximado do índice de consistência quando inseridos outros valores percentuais de FC e MCC.

$$
I C=220,962+F C \times(-39,925)+M C C \times(-50,566)
$$

Em que:

IC = índice de consistência 
$\mathrm{FC}=$ teor de adição de $\mathrm{FC}$ em porcentagem

MCC $=$ teor de adição de MCC em porcentagem

As resistências à compressão das argamassas nas idades de 3, 7, 28 e 56 dias são mostradas na Tabela 5 e Figura 6.

Tabela 5: Resistência à compressão das argamassas.

\begin{tabular}{c|c|c|c|c|c|c|c|c}
\hline \multirow{2}{*}{ ARGAMASSA } & \multicolumn{7}{|c}{ RESISTÊNCIA À COMPRESSÃO (MPa) } \\
\cline { 2 - 9 } & $\mathbf{3}$ dias & $\begin{array}{c}\text { Desvio } \\
\text { padrão }\end{array}$ & $\mathbf{7}$ dias & $\begin{array}{c}\text { Desvio } \\
\text { padrão }\end{array}$ & $\mathbf{2 8}$ dias & $\begin{array}{c}\text { Desvio } \\
\text { padrão }\end{array}$ & $\mathbf{5 6}$ dias & $\begin{array}{c}\text { Desvio } \\
\text { padrão }\end{array}$ \\
\hline REF & 20,74 & 0,79 & 23,63 & 0,41 & 26,78 & 1,7 & 35,05 & 0,99 \\
\hline $0,2 \mathrm{FC}$ & 19,40 & 0,98 & 23,20 & 1,19 & 28,97 & 1,49 & 22,62 & 1,94 \\
\hline $0,3 \mathrm{MCC}$ & 20,42 & 1,36 & 26,07 & 0,65 & 28,50 & 1,65 & 27,80 & 0,87 \\
\hline $0,2 \mathrm{FC}+0,3 \mathrm{MCC}$ & 18,84 & 0,37 & 22,60 & 0,87 & 29,13 & 1,12 & 27,00 & 0,85 \\
\hline $0,1 \mathrm{FC}+0,3 \mathrm{MCC}$ & 21,65 & 0,31 & 22,53 & 0,55 & 29,97 & 0,49 & 26,36 & 0,16 \\
\hline $0,3 \mathrm{FC}+0,3 \mathrm{MCC}$ & 19,95 & 1,27 & 24,12 & 0,56 & 27,76 & 0,56 & 23,94 & 1,02 \\
\hline $0,2 \mathrm{FC}+0,2 \mathrm{MCC}$ & 20,57 & 1,17 & 22,53 & 1,63 & 27,26 & 1,28 & 24,97 & 1,19 \\
\hline $0,2 \mathrm{FC}+0,4 \mathrm{MCC}$ & 20,64 & 0,80 & 23,62 & 1,05 & 25,77 & 1,21 & 24,64 & 1,48 \\
\hline
\end{tabular}




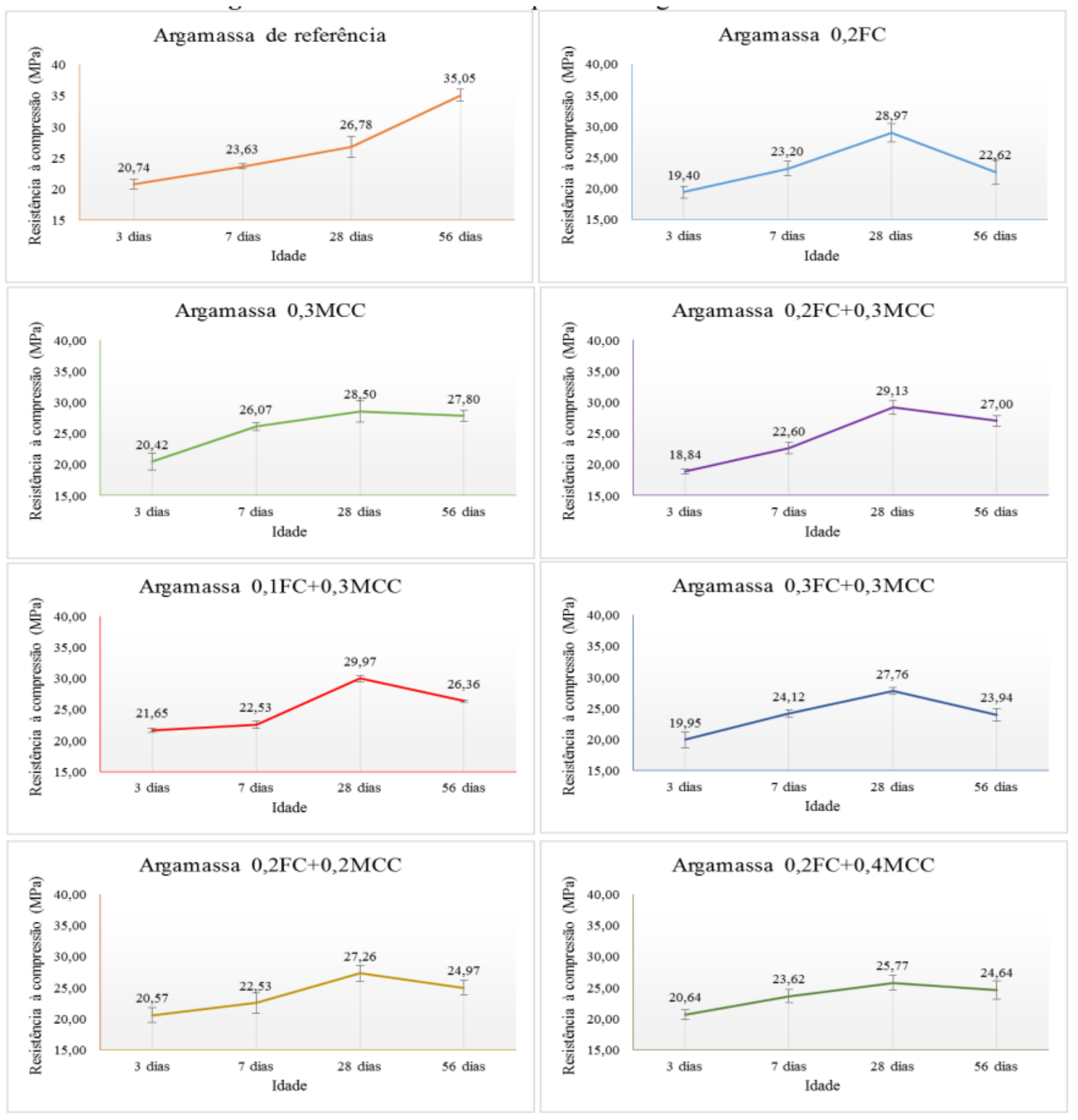

Figura 6: Resistência à compressão das argamassas.

Conforme exposto pela Tabela 5 e a Figura 6, pode-se considerar que houve pequena variação nos resultados de resistência à compressão aos 3 e 7 dias de todas as argamassas, pois todos os valores ficaram próximos. Já os resultados das idades de 28 e 56 dias, demonstrou um comportamento diferente das argamassas. Aos 28 dias somente a argamassa com $0,2 \mathrm{FC}+0,4 \mathrm{MCC}$ teve resistência pouco menor quando comparado ao de referência e todas as outras tiveram acréscimo. Aos 56 dias, as argamassas com adições não apresentaram aumento de resistência à compressão.

Segundo SAVASTANO e AGOPYAN [26], esta redução na resistência à compressão em idades maiores pode estar ligada ao fato de que com a absorção de água pela FC e MCC, ocorre uma interferência na ligação entre a FC e MCC com a matriz cimentícia, o que faz com que ocasione maior porosidade na zona de transição. Quando a FC e MCC absorvem a água da argamassa, como consequência estas aumentam seu volume, sendo assim, quando esta água é liberada ao longo do tempo, a FC e MCC tem uma redução no tamanho. Com esta redução há o aumento do vazio entre as fibras e a matriz cimentícia, levando a uma maior fragilização do material na zona de transição.

Os resultados de resistência à tração na flexão aos 28 dias das argamassas são mostrados na Figura 7. 


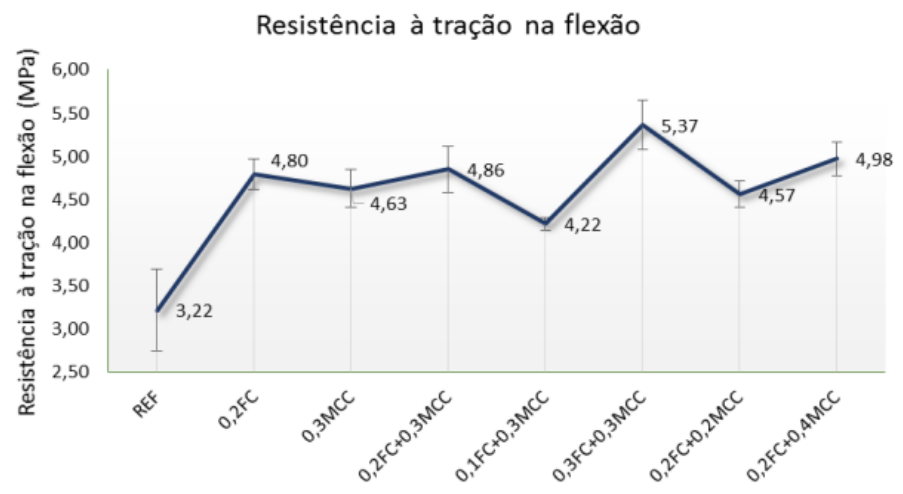

Figura 7: Resistência à tração na flexão aos 28 dias.

Como mostra a Figura 7, todas as argamassas com adições tiveram desempenho superior a argamassa de referência em relação à resistência à tração na flexão. Percebe-se que as argamassas com as maiores adições de FC e MCC apresentaram as maiores resistências à tração na flexão, sendo as argamassas "0,3FC+0,3MCC" e "0,2FC+0,4MCC" com os melhores desempenhos dessa propriedade. Essa análise demonstra que a dupla adição com teores acima de $0,2 \mathrm{FC}$ ou $0,3 \mathrm{MCC}$ melhora o desempenho das argamassas quanto a resistência à tração na flexão.

As argamassas $0,1 \mathrm{FC}+0,3 \mathrm{MCC}$ e $0,2 \mathrm{FC}+0,2 \mathrm{MCC}$, tiveram valores menores que as argamassas com apenas uma adição, o que indica que a dupla incorporação com teores abaixo de $0,2 \mathrm{FC}$ ou $0,3 \mathrm{MCC}$ não apresentaram melhoria no desempenho das argamassas nesta propriedade.

Este ensaio foi realizado apenas aos 28 dias e diante dos resultados obtidos da resistência à compressão aos 56 dias, estes resultados podem apresentar outro comportamento em idades maiores. Possivelmente, a fragilidade na zona de transição que acontece na superfície das adições, também pode vir a influenciar a resistência à tração na flexão das argamassas em idades maiores.

Os resultados obtidos de módulo de elasticidade são mostrados na Figura 8.

Módulo de elasticidade

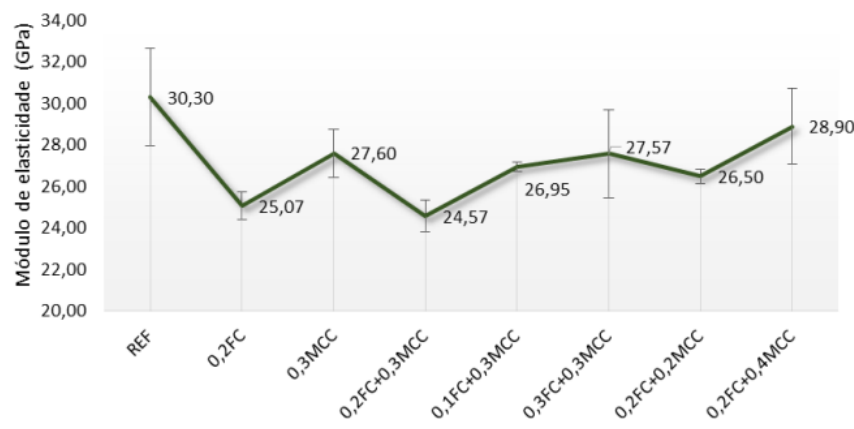

Figura 8: Módulo de elasticidade aos 28 dias.

Conforme mostra a Figura 8, todas as argamassas com adições apresentaram módulo de elasticidade inferior comparado ao da argamassa de referência. Como já exposto, estes valores inferiores podem estar ligados ao fato de que há a incorporação de materiais de baixo módulo de elasticidade na compressão e também pela baixa eficiência da ligação fibra-matriz, o que faz com que ocorra maior quantidade de vazios na zona de transição e consequentemente uma capacidade maior de deformabilidade. Esta propriedade também pode sofrer interferência em idades avançadas assim como ocorreu com a resistência à compressão.

Os valores de absorção, índice de vazios e massas específicas das argamassas são mostradas na Tabela 6. 
Tabela 6: Absorção, índice de vazios e massa específica das argamassas.

\begin{tabular}{|c|c|c|c|c|c|}
\hline ARGAMASSAS & $\begin{array}{c}\text { ABSORÇÃO } \\
\text { (\%) }\end{array}$ & $\begin{array}{l}\text { ÍNDICE DE } \\
\text { VAZIOS (\%) }\end{array}$ & $\begin{array}{l}\text { MASSA ESPECÍ- } \\
\text { FICA DA AMOS- } \\
\text { TRA SECA }\left(\mathbf{g} / \mathrm{cm}^{3}\right)\end{array}$ & $\begin{array}{c}\text { MASSA ESPECÍFICA } \\
\text { DA AMOSTRA SATU- } \\
\text { RADA }\left(\mathbf{g} / \mathrm{cm}^{3}\right)\end{array}$ & $\begin{array}{c}\text { MASSA ESPECÍ- } \\
\text { FICA REAL } \\
\left(\mathbf{g} / \mathbf{c m}^{3}\right) \\
\end{array}$ \\
\hline REF & 7,08 & 14,50 & 2,05 & 2,19 & 2,40 \\
\hline $0,2 \mathrm{FC}$ & 8,24 & 16,50 & 2,00 & 2,17 & 2,40 \\
\hline $0,3 \mathrm{MCC}$ & 7,59 & 15,29 & 2,01 & 2,17 & 2,38 \\
\hline $0,2 \mathrm{FC}+0,3 \mathrm{MCC}$ & 8,11 & 16,46 & 2,03 & 2,19 & 2,43 \\
\hline $0,1 \mathrm{FC}+0,3 \mathrm{MCC}$ & 8,75 & 17,39 & 1,99 & 2,16 & 2,41 \\
\hline $0,3 \mathrm{FC}+0,3 \mathrm{MCC}$ & 8,91 & 17,76 & 1,99 & 2,17 & 2,42 \\
\hline $0,2 \mathrm{FC}+0,2 \mathrm{MCC}$ & 8,60 & 17,27 & 2,01 & 2,18 & 2,43 \\
\hline $0,2 \mathrm{FC}+0,4 \mathrm{MCC}$ & 9,20 & 18,25 & 1,98 & 2,17 & 2,43 \\
\hline
\end{tabular}

Conforme mostra a Tabela 6, as argamassas que têm os maiores teores de adição, 0,3FC+0,3MCC e $0,2 \mathrm{FC}+0,4 \mathrm{MCC}$, foram as que tiveram maiores valores de absorção e índice de vazios. A argamassa com adição que teve o menor valor de absorção e índice de vazios foi a $0,3 \mathrm{MCC}$, o que evidencia que a $\mathrm{FC}$ tem maior capacidade de absorver água, devido seu tamanho ser maior que a MCC.

Com relação aos valores obtidos de massas específicas, uma pequena variação pode ser observada, o que demonstra assim, que as adições não influenciam de forma significativa nesta propriedade.

As análises com MEV foram realizadas nas argamassas com MCC e FC, porém não foi possível identificar a MCC na amostra. Sendo assim, prosseguiu-se a análise somente com a amostra com FC. A Figura 9 mostra uma imagem obtida no MEV de uma amostra com FC.

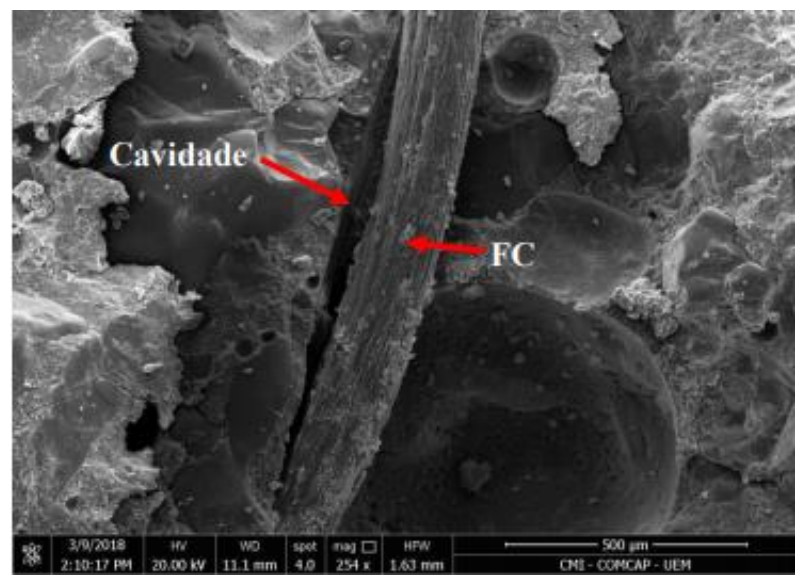

Figura 9: MEV da argamassa com FC com magnificação de 254x

Conforme mostra a Figura 9, é possível identificar falhas na aderência da fibra com a matriz cimentícia, fato este que pode justificar a diminuição dos valores de resistência à compressão aos 56 dias.

Uma outra imagem foi feita no MEV para realizar a análise com o EDS. A Figura 10 mostra a imagem da amostra com a área demarcada que foi realizado o EDS. Esta área se trata da face da FC. 

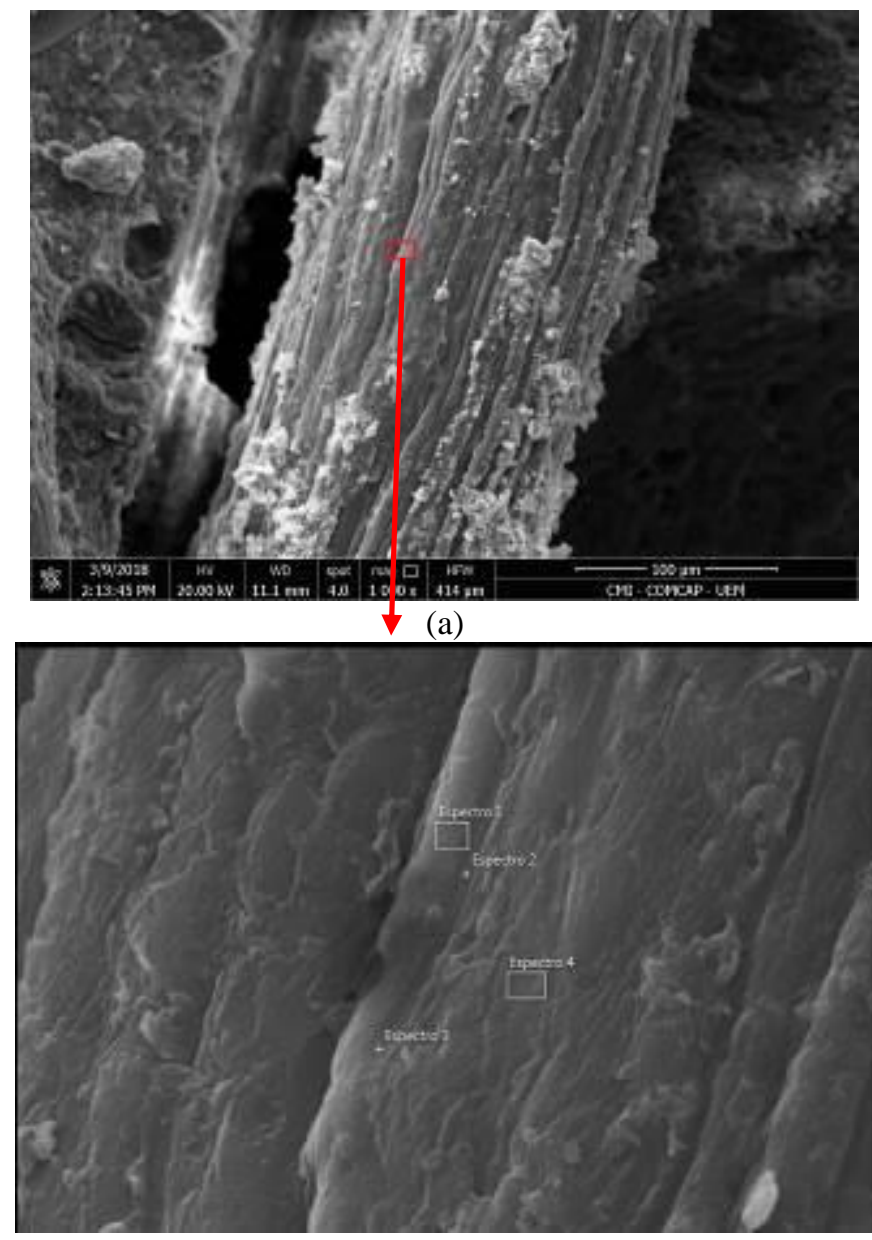

(b)

Figura 10: (a) MEV da argamassa com FC com magnificação de 1000X; (b) imagem EDS com os espectros da área demarcada.

A Tabela 7 mostra os componentes encontrados nos espectros analisados.

Tabela 7: EDS da argamassa com FC

\begin{tabular}{c|c|c|c|c|c}
\hline ESPECTRO & $\mathbf{C}$ & $\mathbf{O}$ & $\mathbf{C a}$ & $\mathbf{K}$ & $\mathbf{S i}$ \\
\hline 1 & 45,2 & 33,3 & 5,3 & 2,5 & 1,2 \\
\hline 2 & 37,6 & 44,5 & 12,2 & 7,8 & 1,6 \\
\hline 3 & 48,1 & 43,5 & 8,4 & 3,1 & 1,1 \\
\hline 4 & 43,3 & 24,6 & 7,6 & 3,7 & 1,5 \\
\hline
\end{tabular}

Conforme mostra a Tabela 7, o EDS realizado na face da FC apontou os seguintes compostos: carbono, oxigênio, cálcio, potássio e silício. $\mathrm{O}$ alto teor de oxigênio e carbono pode ser atribuído ao fato de que se trata de um material orgânico, o potássio também é encontrado em fibras naturais e o cálcio e o silício pode ser proveniente dos grãos de cimento aderidos nas fibras.

A Figura 11 mostra a mesma imagem da Figura 10, mas com outra área demarcada para a análise com o EDS. Desta vez, a análise foi feita na argamassa e na interface em que a FC estava em contato, com o objetivo de verificar as fases existentes na zona de transição entre a FC e a matriz cimentícia. 


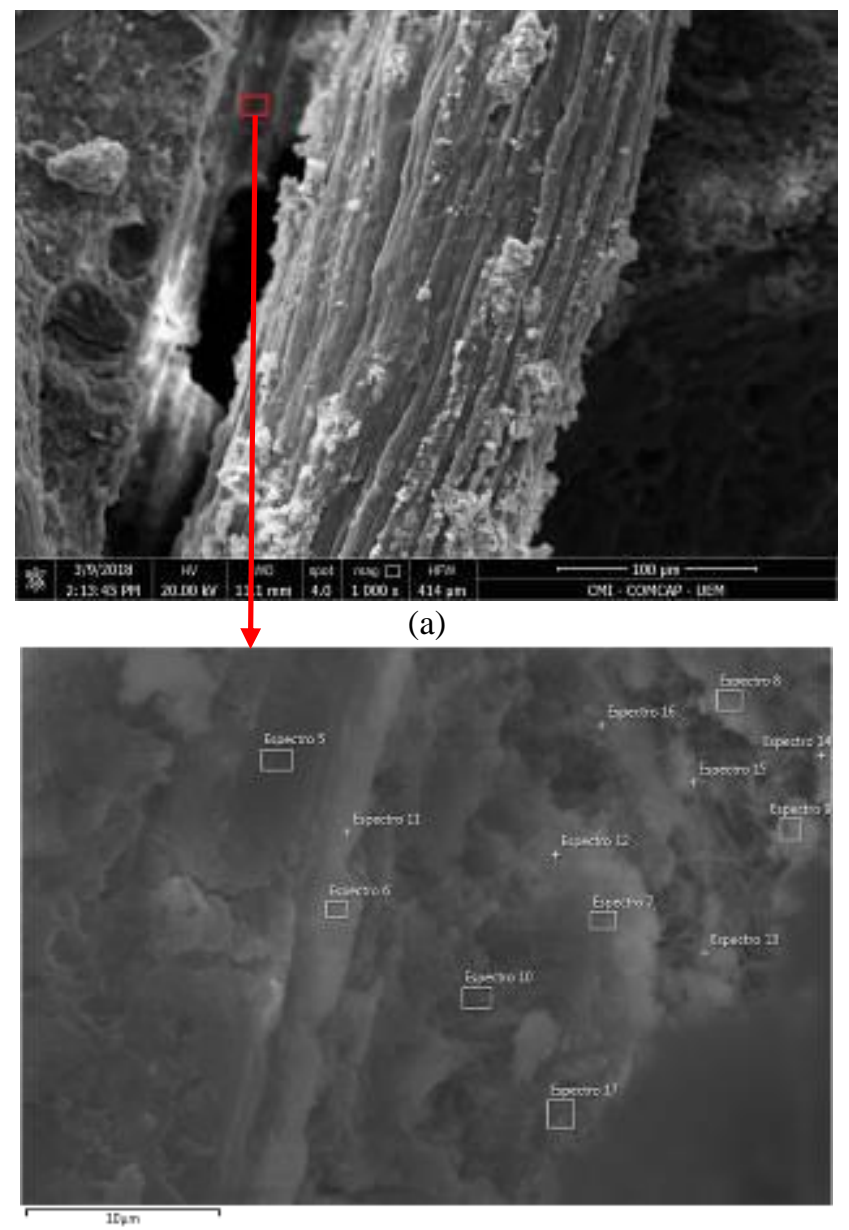

(b)

Figura 11: (a) MEV da argamassa com FC com magnificação de 1000x; (b) EDS da argamassa com FC da área demarcada.

A Tabela 8 mostra os componentes encontrados nos espectros, as relações e as fases.

Tabela 8: Fases - análise com EDS.

\begin{tabular}{c|c|c|c|c|c|c|c}
\hline ESPECTRO & $\mathbf{C a}$ & $\mathbf{S i}$ & $\mathbf{A l}$ & $\mathbf{F e}$ & $\mathbf{S i} / \mathbf{C a}$ & $(\mathbf{A l + F e}) / \mathbf{C a}$ & FASE \\
\hline 5 & 50,1 & 2,2 & 0 & 6,0 & 0,04 & 0,1 & $\mathrm{CH}$ \\
\hline 6 & 52,0 & 1,2 & 0 & 7,2 & 0,02 & 0,1 & $\mathrm{CH}$ \\
\hline 7 & 47,2 & 1,6 & 0 & 5,9 & 0,03 & 0,1 & $\mathrm{CH}$ \\
\hline 8 & 54,1 & 1,3 & 0,4 & 8,6 & 0,02 & 0,2 & Etringita \\
\hline 9 & 48,2 & 2,1 & 0,6 & 12,7 & 0,04 & 0,3 & Etringita \\
\hline 10 & 57,6 & 1,9 & 0,5 & 5,1 & 0,03 & 0,1 & $\mathrm{CH}$ \\
\hline 11 & 54,3 & 2,3 & 0,5 & 6,1 & 0,04 & 0,1 & $\mathrm{CH}$ \\
\hline 12 & 48,0 & 2,1 & 0,5 & 9,9 & 0,04 & 0,2 & Etringita \\
\hline 13 & 51,0 & 1,3 & 0 & 15,4 & 0,03 & 0,3 & Etringita \\
\hline 14 & 47,6 & 1,5 & 0,7 & 7,8 & 0,03 & 0,2 & Etringita \\
\hline 15 & 59,7 & 0,8 & 0,3 & 20,0 & 0,01 & 0,3 & Etringita \\
\hline 16 & 50,2 & 1,4 & 0,6 & 20,2 & 0,03 & 0,4 & Etringita \\
\hline 17 & 41,1 & 2,7 & 0,8 & 4,3 & 0,07 & 0,1 & CH \\
\hline
\end{tabular}

Como pode ser observado na Tabela 8 , não foi encontrada nesta parte analisada, a fase mais importan- 
te para a resistência da argamassa que é o C-S-H. Frente a isto, é provável que a adição de fibras naturais interfira nos produtos de hidratação do cimento, além de não promover uma boa ligação com a matriz cimentícia.

\section{CONCLUSÕES}

O objetivo desta pesquisa foi o de avaliar a influência da adição de FC e MCC em misturas de argamassa cimentícia. Diante do exposto, foi possível concluir que:

- O tratamento da FC, neste caso a fervura e lavagem com água, alteram as características da superfície das fibras, tornando-as mais compactas e aparentemente enrijecidas, podendo produzir alterações significativas em suas propriedades mecânicas e de durabilidade no meio cimentício. É importante investigar formas mais eficientes de tratamento da FC e suas consequências nas propriedades das argamassas.

- O índice de consistência das argamassas com adições diminui conforme aumenta os teores de adições, devido ao caráter altamente hidrofílico da FC e da MCC. Desta forma, a definição do traço deve ser analisada para que se obtenha uma boa trabalhabilidade sem que ocorram perdas significativas na resistência mecânica. O traço em massa utilizado neste estudo, 1:3:0,52 (cimento:agregado miúdo:água/cimento), pode ser considerado viável do ponto de vista de trabalhabilidade nos teores de FC e MCC testados. Contudo, para se obter argamassas com maiores resistências mecânicas, o uso de aditivo é indispensável.

- Em relação à resistência à compressão, as adições de FC e MCC não promoveram alterações consideráveis nas resistências à compressão para as idades iniciais da argamassa, ou seja, 3 e 7 dias. Já para a idade de 28 dias, que é considerada a idade de referência nos modelos de dimensionamento de estruturas de concreto, as argamassas com adições apresentaram resistências à compressão pouco superiores a argamassa de referência. Porém, para a idade de 56 dias, as argamassas com adições apresentaram resistências à compressão menores quando comparada as resistências aos 28 dias, e bem inferiores à resistência à compressão da argamassa de referência. Conclui-se que para maiores idades, a FC e a MCC não contribui para o crescimento da resistência à compressão.

- Em relação à resistência à tração na flexão realizada aos 28 dias, os resultados demonstraram que todas as argamassas com adições tiveram valores superiores quando comparados à argamassa de referência. Conclui-se que a dupla adição com teores acima de $0,2 \mathrm{FC}$ ou $0,3 \mathrm{MCC}$ melhora de forma significativa o desempenho das argamassas quanto à resistência à tração na flexão. No entanto, a fragilidade na zona de transição que acontece na superfície da FC, pode vir a influenciar negativamente a resistência à tração na flexão das argamassas em idades maiores que 28 dias, o que deve ser melhor investigado.

- Quanto ao módulo de elasticidade, todas as argamassas com adições apresentaram desempenho inferior comparadas a argamassa de referência. Conclui-se que as adições de FC e MCC promovem a diminuição do módulo de elasticidade das argamassas, que pode ser explicado pelo fato de que as adições, FC e MCC, são materiais de baixo módulo de elasticidade na compressão e provável baixa eficiência da ligação fibramatriz, o que faz com que ocorra maior quantidade de vazios e consequentemente uma capacidade maior de deformabilidade.

- As análises realizadas com o MEV e o EDS, demonstraram a falta de ligação da fibra com a matriz cimentícia. A fibra não aderiu de forma efetiva ao material cimentício. Também, na parte analisada, não foi encontrada a fase C-S-H que é a mais importante para a argamassa. Desta forma, é provável que a FC interfere nos produtos de hidratação do cimento, trazendo como consequência uma maior fragilização da argamassa na interface fibra-matriz.

Diante de todos os resultados encontrados, pode-se considerar que as incorporações de FC e MCC melhoram de forma significativa a resistência à tração na flexão de argamassas, porém não contribuem de forma positiva nas outras propriedades mecânicas das argamassas, mas sem prejuízos significativos para sua utilização. É recomendável estudos de argamassas com FC e MCC em longo prazo para verificar se as propriedades mecânicas sofrem influências significativas com a idade.

\section{AGRADECIMENTOS}

O presente trabalho foi realizado com apoio da Coordenação de Aperfeiçoamento de Pessoal de Nível Superior - Brasil (CAPES) - Código de financiamento 001.

\section{BIBLIOGRAFIA}

[1] FIGUEIREDO, A. D., "Concreto reforçado com fibras”, Tese de D. Sc., Curso de Engenharia de Construção Civil, Escola Politécnica da Universidade de São Paulo, São Paulo, SP, Brasil, 2011. 
[2] MARINELLI A. L., MONTEIRO M. R., AMBRÓSIO J. D., et al., "Desenvolvimento de compósitos poliméricos com fibras vegetais naturais da biodiversidade: uma contribuição para a sustentabilidade amazônica", Poliméricos: Ciência e Tecnologia, v. 18, n 2, pp. 92-99, 2008.

[3] CORREA, M.U. Árvore do conhecimento: coco,

http://www.agencia.cnptia.embrapa.br/gestor/coco/arvore/CONT000giw3qz5o02wx5ok05vadr1u5iye30.html. Acessado em janeiro de 2018.

[4] MOTTA, L. A. de C., AGOPYAN, V., JOHN V. M., Caracterização de fibras curtas empregadas na construção Civil, São Paulo, EPUSP, 2007.

[5] YAN, L., SU, S., CHOUW, N., "Microstructure, flexural properties and durability of coir fibre reinforced concrete beams externally strengthened with flax FRP composites", Composites Part B: Engineering, v. 80, pp.343-354, out. 2015.

[6] BLEDZKI, A. K., GASSAN, J., "Composites reinforced with cellulose based fibres", Progress in Polymer Science, v. 24, pp. 221-274, 1999.

[7] KWAN, W. H., RAMLI, M., CHEAH, C. B., "Flexural strength and impact resistance study of fibre reinforced concrete in simulated aggressive environment", Construction And Building Materials, v. 63, pp.62-71, jul. 2014.

[8] SILVA, E. J., et al., "Resistência à compressão de argamassas em função da adição de fibra de coco", Revista Brasileira de Engenharia Agrícola e Ambiental, v. 18, n. 12, pp.1268-1273, dez. 2014.

[9] ABNT - ASSOCIAÇÃO BRASILEIRA DE NORMAS TÉCNICAS. NBR 6118 -Projeto de estruturas de concreto - procedimento. Rio de Janeiro - RJ, 2014.

[10] HOYOS G. C., CRISTIA E., VÁSQUEZ A., "Effect of cellulose microcrystalline particles on properties of cement based composites", Materials \& Design, v. 51, pp. 810-818, out. 2013.

[11] ALI, M., LIU, A., SOU, H., et al., "Mechanical and dynamic properties of coconut fibre reinforced concrete", Construction and Building Materials, v.30, pp.814-825, 2012.

[12] ASASUTJARIT, C., et al., "Development of coconut coir-based lightweight cement board", Construction And Building Materials, v. 21, n. 2, pp.277-288, fev. 2007.

[13] ASSOCIAÇÃO BRASILEIRA DE NORMAS TÉCNICAS, ABNT NBR NM 52, Agregado miúdo Determinação de massa específica e massa específica aparente, Rio de Janeiro - RJ, 2009.

[14] ASSOCIAÇÃO BRASILEIRA DE NORMAS TÉCNICAS, ABNT NBR NM 45, Agregados - Determinação da massa unitária e do volume de vazios, Rio de Janeiro - RJ, 2006.

[15] ASSOCIAÇÃO BRASILEIRA DE NORMAS TÉCNICAS, ABNT NBR NM 248, Agregados - determinação da composição granulométrica, Rio de Janeiro - RJ, 2003.

[16] TOLEDO FILHO, R. D., "Materiais compósitos reforçados com fibras naturais: Caracterização experimental", Tese de D. Sc., DEC-PUC/DEC, Rio de Janeiro, RJ, Brasil, 1997.

[17] CAO, Y., et al., "The influence of cellulose nanocrystal additions on the performance of cement paste", Cement And Concrete Composites, v. 56, p.73-83, fev. 2015.

[18] SILVA, L. F., "Estudo do efeito da microcelulose sobre o desempenho de materiais compósitos de matriz cimentícia", Dissertação de M. Sc., PEU/UEM, Maringá, PR, Brasil, 2016.

[19] ASSOCIAÇÃO BRASILEIRA DE NORMAS TÉCNICAS, ABNT NBR 7215, Cimento Portland - Determinação da resistência à compressão, Rio de Janeiro - RJ, 1997.

[20] ASSOCIAÇÃO BRASILEIRA DE NORMAS TÉCNICAS, NBR 13279, Argamassa para assentamento e revestimento de paredes e ABNT tetos - Determinação da resistência à tração na flexão e à compressão, Rio de Janeiro - RJ, 2005.

[21] ASSOCIAÇÃO BRASILEIRA DE NORMAS TÉCNICAS, ABNT NBR 8522, Concreto - Determinação do módulo estático de elasticidade à compressão, Rio de Janeiro - RJ, 2017.

[22] ASSOCIAÇÃO BRASILEIRA DE NORMAS TÉCNICAS, ABNT NBR 9778, Argamassa e concreto endurecidos - Determinação da absorção de água, índice de vazios e massa específica, Rio de Janeiro - RJ, 2009.

[23] TAYLOR, H.F.W., NEWBURY, D.E., "An electron microprobe study of a mature cement paste”, $\mathrm{Ce}$ ment and Concrete Research, v.14, pp.565-73, 1984. 
[24] BASTOS, P.S.S., "Análise experimental de dormentes de concreto protendido reforçados com fibras de aço", Tese de D. Sc., Escola de Engenharia de São Carlos, Universidade de São Paulo, São Carlos, SP, Brasil, 1999.

[25] CAPELIN, L. J., "Análise de argamassa cimentícia com adição de fibra de coco e microcelulose cristalina”, Dissertação de M. Sc., PEU/UEM, Maringá, PR, Brasil, 2018.

[26] SAVASTANO J. H., AGOPYAN, V., "Transition zone studies of vegetable fibre-cement paste composites”, Cement \& Concrete Composites, v. 21, pp.49-57, 1999.

\section{ORCID}

Luana Jéssica Capelin

Katherine Kaneda Moraes

João Paulo Zampieri

Romel Dias Vanderlei https://orcid.org/0000-0002-2954-9465

https://orcid.org/0000-0003-4461-850X

https://orcid.org/0000-0001-9834-1820

https://orcid.org/0000-0001-5676-6951 